\title{
Adherence to Healthy Lifestyle among Hypertensive Patients in Harar Region, Eastern Ethiopia \\ Atnafu Nega Nadewu ${ }^{1 *}$ and Biftu Geda ${ }^{2}$
}

${ }^{1}$ Department of Nursing, College of Medicine and Health Science, Wolaita Sodo University, Wolaita Sodo Ethiopia ${ }^{2}$ School of Nursing and Midwifery, Haramaya University, Harar, Ethiopia

\begin{abstract}
Background: Hypertensive adults poorly adhere to proper treatment and the recommended lifestyles. This study sought to determine the status of adherence to the recommended healthy lifestyles and its affecting factors.

Methods: An institution based cross-sectional study was conducted among the hypertensive patients of age 18 years and above who were receiving an antihypertensive treatment at the Hiwot Fana and Jugola hospitals. The single population proportion formula was used to estimate the total sample size of 422 study subjects. The World Health Organization stepwise approach to the non-communicable disease risk factor surveillance based questionnaire was used to label the patient as adherent and non-adherent to the healthy lifestyle. Bivariate logistic regression was carried out to check the effect of independent variables on adherence. Finally, multivariate logistic regression was carried out to minimize the confounding variables and effect modifiers with $P$ value $<0.05$ at $95 \%$ confidence interval.

Result: An adherence to the healthy lifestyle was $62.1 \%$. Each patient was adherent to at least one recommendation and only $28.7 \%$ of the respondents were adherent to all the recommended six healthy lifestyles. From all respondents; $62.3 \%$ were adherent to the exercise, $81.8 \%$ were adherent to the diet, $81.5 \%$ were adherent to the tobacco, $95.8 \%$ were adherent to the alcohol, $98.5 \%$ were adherent to the salt and $56.4 \%$ met the ideal body weight or body mass index. Marital status, educational level, distance, blood pressure control, hospital visit and Khat chewing were significantly associated with adherence to the recommended healthy lifestyle.

Conclusion: Adherence to the recommended lifestyle was far below the recommendation. Emphasis should be given to the awareness creation, its complications and the nearby service; thereby increase adherence behavior of hypertensive patients. Moreover, there is a greater need for behavioural change communication in the region.
\end{abstract}

Keywords: Hypertension; Healthy lifestyle; Adherence; Eastern Ethiopia

\section{Introduction}

Hypertension (HTN) is raised pressure exerted at blood vessel by the circulating blood. This is often measured as systolic when the heart contracts and diastolic when it relaxes; which is ranked in terms of millimeters of mercury and written as systolic over diastolic. Arterial Blood Pressure (BP) is normal when the systolic is between 90-139 $\mathrm{mmHg}$ and the diastolic is between $60-89 \mathrm{mmHg}$. Hypertension is operationalized for the clinical and research decision as to when either of the systole or the diastole or both above the normal range. It should be measured twice or more in the sitting position and the average reading is taken [1-3]. The causes of hypertension is unknown in about $95 \%$ of the hypertensive patients [1].

In 2008, nearly one billion adults aged 25 and above were diagnosed with the hypertension. Even though there is disparity between the studies, one meta-analysis estimated the national prevalence of hypertension in the Ethiopia as $19.6 \%[4,5]$. As the age advances the prevalence of hypertension increases; and it closes to $50 \%$ among the elder people of 60-69 years of age. The figure increases to $75 \%$ among the elder of 70 years and above. Significant heritable of the BP level among the family and the twin studies are documented $[2,6,7]$.

Hypertension is the preventable cause of the cardiovascular disease morbidity and mortality. It causes around 7.1 million deaths each year, nearly $13 \%$ of all deaths. It is ranked third as the cause of disabilityadjusted life-years. Nearly $62 \%$ of the cerebrovascular disease and $49 \%$ of the ischemic heart disease burden in the worldwide are caused by the high BP [2,5,8-11]. Hypertension is the manageable risk factor for the coronary heart disease, stroke, congestive heart failure, end-stage renal disease and the peripheral vascular disease $[2,10,12,13]$.
Hypertension is easily diagnosed with the blood cuff so-called sphygmomanometers. However, its awareness is too low due to its silence nature. It can be treated effectively with pharmacological therapy and lifestyle modifications. The latter is recommended for all the hypertensive patients regardless of their stage of the hypertension and the drug therapy. Stick to the healthy lifestyle lessen, or even end, the need for antihypertensive drug treatment among the hypertensive patient $[1,7,9,14]$.

The ultimate goal of the treatment to the hypertension is to control BP: below 140/90 mmHg. The adequate control of the BP has been associated with the mean reductions of more than $50 \%$ in the incidence of the congestive heart failure, more than $20 \%$ in the myocardial infarction and also more than $35 \%$ in the stroke $[7,15-$ 17]. Nevertheless, less than quarter of the hypertensive patients have been met this target [18-21]. Even with the convenience of the several effective hypertensions managements, uncontrolled HTN leftovers are the challenging clinical problem in the worldwide.

Different studies showed that non-adherence to the antihypertensive therapy is the most key reason for the uncontrolled BP [22,23]. Non-

*Corresponding author: Atnafu Nega Nadewu, Department of Nursing, College of Medicine and Health Science, Wolaita Sodo University, Wolaita Sodo, Ethiopia, Tel: +251913708048; E-mail: atnenag@yahoo.com

Received: July 27, 2018; Accepted: September 30, 2018; Published: October 07, 2018

Citation: Nadewu AN, Geda B (2018) Adherence to Healthy Lifestyle among Hypertensive Patients in Harar Region, Eastern Ethiopia. Prim Health Care 8: 308. doi: 10.4172/2167-1079.1000308

Copyright: (c 2018 Nadewu AN, et al. This is an open-access article distributed under the terms of the Creative Commons Attribution License, which permits unrestricted use, distribution, and reproduction in any medium, provided the original author and source are credited. 
adherence to the recommended lifestyle plays the major portion of the cause of uncontrolled HTN and could not be neglected.

Most of the studies on the adherence focus over the adherence to antihypertensive medication, but the lifestyle modification is also as important as antihypertensive medication. The effective lifestyle modification can lower the BP as much as the single antihypertensive drug [2]. The research findings demonstrate that weight loss, reduced alcohol and sodium intake, cessation of smoking and regular physical activity are effective healthy lifestyle adaptation to reduce the BP. The studies also show that diets high in fruits, vegetables and low-fat dairy products can prevent the development of the HTN and can also lower the elevated BP [3]. It is documented that the adherence to these healthy lifestyles is associated with a low risk of the sudden cardiac death $[24,25]$.

With this all the evidence regarding the benefits of the healthy lifestyle, studies reveal adherence to these recommendations among the HTN patients is poor [26-28].

The national guideline of the country recommends both pharmacological and non-pharmacological interventions for the patient with the hypertension. The latter being prioritized and suggest for all the patients with any class of hypertensive with good the adherence. The guideline recommended healthy lifestyle includes healthy weight (reduction of body weight to normal BMI), physical activity, restriction of salt, cessation of smoking, high fruit and vegetable and low fat and oily diets and limit alcohol intake [29].

However different national study conducted reveal adherence to the healthy lifestyle is far below to optimum. The real factors behind poor adherence to healthy lifestyles were inadequately pointed. Unhealthy and other non-clearly associated (but believed to affect health) behavior were commonly practiced in eastern Ethiopia and specifically in the study area. The excess alcohol intake, smoking cigarette, chewing Khat and others non-stated are common practices [30-32]. We looked at factors that affect the adherence to the healthy lifestyle among hypertensive patients attending the selected hospitals in the Harari region.

\section{Methods}

\section{Study design and setting}

An institution-based, cross-sectional study was conducted from February to March 2015 at Hiwot Fana and Jugola hospitals in Harar town. Harar is found at $526 \mathrm{~km}$ east of Addis Ababa, the countr's capital. In the last census the Zone had a total population of 205,000. The health service coverage of the town was $100 \%$ with four governmental hospitals: two public hospitals (Hiwot Fana specialized university hospital and Jugola hospitals), one Federal police hospital, one army or Defense hospital, two private hospitals, eight governmental Health Centers, 16 Health posts [15].

The study populations were adult patients who were on follow-up in those hospitals during the study period. The sample was calculated by using single population proportion formula. By taking the proportion of adherence $50 \%$, with $5 \%$ margin of error, $95 \% \mathrm{CI}$ and $10 \%$ non-response rate the total sample size was calculated to be 422 . Using systematic random sampling method; every second hypertensive patient visiting the facilities both at inpatient and outpatient departments who were known to be hypertensive patients for one year and above were selected. The number of patients sampled from each hospital was proportional to the total number of patients thereof.

\section{Operational definition}

- Adherence to the healthy lifestyle is measured using the six recommended lifestyles. These are lifestyle advised by JNC 7 to prevent and manage hypertension and include; exercise, Diet Allowance to Stop Hypertension (DASH) diet, moderation of alcohol intake, reduction of dietary sodium, cessation of smoking and maintaining healthy weight. In this study, the respondents who adhere to at least five out of six healthy lifestyles were considered as adherent otherwise non-adherent.

- Exercise-related healthy lifestyle is physical activities which increase breathing or heart rate within the month, including brisk walking, jogging or running, riding a bicycle or exercise bicycle, swimming, aerobic exercise, aerobic dancing and the like. If the respondent is answered yes to the exercise question, he/she were considered as adherent to exercise recommendation.

- Diet allowance to stop hypertension related healthy lifestyle assessed by "do you eat fruit, vegetable, whole grain and lowfat diet at least 3 times per a week?" question. The respondent who reported yes were considered as adherent to the diet recommendation.

- Alcohol-related healthy lifestyle is daily consumption of fewer than $30 \mathrm{~mL}$ net alcohol. The net alcohol is calculated from the type of alcoholic beverage consumed based on their net alcohol percent and volume of alcohol consumed habitually.

- Salt related healthy lifestyle is defined as consumption of never or less than $6 \mathrm{~g}$ salt per food palate. The metric-measurement system is converted to the equivalent household measurement system (thus never or less than half teaspoon) for data collection.

- Smoking-related healthy lifestyle is defined as self-report of never smoked or stopped smoking before 12 months.

- The healthy weight is when the calculated BMI of the individual is within the range of 18.5 and 24.9 form the measured height and weight.

\section{Data collection tools and procedures}

Data was collected using standardized pre-tested intervieweradministered questionnaire adapted from WHO STEP surveillance. The questionnaire was translated to Amharic (the local language) and then translated back to English by the language expert from Haromaya University Department of Foreign Language to maintain conceptual consistency. The BP was measured using mercury sphygmomanometer with cuff size of $23 \times 12.5 \mathrm{~cm}$ and stethoscope after the participants rested for $10 \mathrm{~min}$. The exit interview was carried out for those who are at the outpatients and after daily morning round for those who are in the inpatient. In addition, the patient medical record was also reviewed for the additional information.

\section{Data processing and analysis}

The filled questionnaires were checked for completeness and entered into Epi Info version 6 and then exported to the SPSS version 20 for further analysis. The descriptive statistic was used to describe the study population in relation to the relevant variables. Both the bivariate and the multivariate logistic regression models were used to identify the associated factors. The Odds Ratios and its 95\% Confidence Intervals were computed from multivariate logistic regression and the variables 
with the p-value less than 0.05 were considered as the significantly associated with the outcome variable.

\section{Quality control}

The data were collected by professional nurses who have clinical experiences. The data quality was controlled by giving training and appropriate supervisions for the data collectors. The overall supervision was carried out by the principal investigator. The pre-test was done using five percent of the questionnaire among the $5 \%$ of sample population in Chiro Hospital; which is $198 \mathrm{~km}$ distance from actual data collection site. Appropriate modifications were made after analyzing the pretest result before the actual data collection. To keep the validity of data collection instruments, measurements were taken with the same instruments during pretest. BP was measured twice on sitting position to obtain reliable data.

\section{Ethical Considerations}

The ethical clearance was obtained from the Haromaya University after institutional research review committees of Haromaya University approve the study. Communication with the corresponding hospital administrators was made through the formal letter obtained from the health bureau. The measurements were taken only after the written consent was obtained from the study participants. The confidentiality was maintained by making the data collection procedure anonymous.

\section{Results}

\section{Socio-demographic characteristics}

Out of the expected 422 respondents, 401 participated in the study, yielding a response rate of $95 \%$. Of the total sample, $212(52.9 \%)$ respondents were from the Hiwot Fana Specialized University Hospital and the rest (47.1\%) were from the Jugola Hospital.

The mean age of the respondents was $58.6(\mathrm{SD}=12.8)$ years. The majority $(63.1 \%)$ of the respondents were female and more than one third $(70.6 \%)$ of the respondents were married. Nearly half $(51 \%)$ of them identified Orthodox as their religion. Nearly half (196/48.9\%) of the respondents were Amhara by ethnicity. Nearly half (47.1\%) of them have no formal education. From the total, $42.7 \%$ of the respondents resided less than one kilometer from their corresponding hospital (Table 1).

\section{$\mathrm{BP}$ and related conditions}

Of the total, $182(45.4 \%)$ of the respondents were aware of their hypertensive condition within the last 5 years while 77 (19.2\%) were aware 10 years ago, about their hypertensive condition. From the total, $133(33.2 \%)$ of the respondents either didn't know their initial BP category or not recorded on the patient record chart. The remaining respondents' initial BP was categorized: $61.1 \%$ as Stage 2, 24.7\% as Stage 1 and $1 \%$ as pre-HTN according to the Seventh Report of Joint National Committee prevention, detection, evaluation and treatment of high blood pressure (JNC7). Majority 227 (56.6\%) of the respondents have Stage $1 \mathrm{BP}$ category during data collection as of JNC7 classification; whereas 68 (17\%) of the respondents were Stage 2 category for HTN. Regarding the comorbidity report; $109(27.2 \%)$ of the respondents have no chronic comorbidity. Diabetes mellitus, renal disease, peptic ulcer were the most commonly reported comorbidities among the respondents. Only $22.2 \%$ (89) of respondents have their BP under control. Nearly the Quarter (26.9\%) of the respondents have the family history of HTN, 160 (39.9\%) have no family history and the rest $33.2 \%$ (133) don't know family history. Almost all (98\%) of the respondents

\begin{tabular}{|c|c|c|c|}
\hline \multicolumn{2}{|l|}{ Variables } & \multirow{2}{*}{\begin{tabular}{|c|} 
Frequency \\
22 \\
\end{tabular}} & \multirow{2}{*}{\begin{tabular}{|c} 
Percentage \\
5.5
\end{tabular}} \\
\hline \multirow{3}{*}{ Age (year) } & $18-39$ & & \\
\hline & $40-60$ & 167 & 41.6 \\
\hline & $60+$ & 212 & 52.9 \\
\hline \multirow{5}{*}{ Marital status } & Single & 10 & 2.5 \\
\hline & Married & 283 & 70.6 \\
\hline & Divorced & 25 & 6.2 \\
\hline & Widowed & 70 & 17.5 \\
\hline & Separated & 13 & 3.2 \\
\hline \multirow{4}{*}{ Religion } & Muslim & 153 & 38.15 \\
\hline & Protestant & 40 & 10 \\
\hline & Orthodox & 207 & 51.6 \\
\hline & Others & 1 & 0.25 \\
\hline \multirow{4}{*}{ Ethnicity } & Amhara & 196 & 48.9 \\
\hline & Harari & 63 & 15.7 \\
\hline & Oromo & 121 & 30.17 \\
\hline & Other & 21 & 5.23 \\
\hline \multirow{5}{*}{ Educational status } & Illiterate (can't read \& write) & 129 & 32.1 \\
\hline & Illiterate (can read \& write) & 60 & 15 \\
\hline & Primary (1-8) & 114 & 28.4 \\
\hline & Secondary (9-12) & 76 & 19 \\
\hline & College/University & 22 & 5.5 \\
\hline \multirow{8}{*}{ Job } & Governmental organization & 68 & 17 \\
\hline & Non-governmental organization & 33 & 8.2 \\
\hline & Housewife & 144 & 35.9 \\
\hline & Farmer & 36 & 9 \\
\hline & Merchant & 41 & 10.2 \\
\hline & Daily laborer & 27 & 6.7 \\
\hline & Student & 2 & 0.5 \\
\hline & Other & 50 & 12.5 \\
\hline \multirow{3}{*}{$\begin{array}{l}\text { The distance of } \\
\text { residence from } \\
\text { hospital }\end{array}$} & Less than $1 \mathrm{~km}$ & 171 & 42.6 \\
\hline & $1 \mathrm{~km}$ to $2.99 \mathrm{~km}$ & 115 & 28.7 \\
\hline & $3 \mathrm{~km}$ and above & 115 & 28.7 \\
\hline \multirow{3}{*}{ Cost sharing } & Governmental organization & 300 & 74.8 \\
\hline & Nongovernmental organization & 14 & 3.5 \\
\hline & Self \& family & 87 & 21.7 \\
\hline \multirow{3}{*}{ Monthly income } & Less than 300 birrs & 144 & 35.9 \\
\hline & 300 to 700 birrs & 161 & 40.2 \\
\hline & 700 birr and more & 96 & 23.9 \\
\hline \multirow{3}{*}{ Years after diagnosis } & $1-5$ & 182 & 45.4 \\
\hline & $6-10$ & 142 & 35.4 \\
\hline & $10+$ & 77 & 19.2 \\
\hline
\end{tabular}

Table 1: Socio-demographic characteristics of hypertensive patients attending Hiwot Fana Specialized University Hospital and Jugola Hospital from February 13 to March 16, 2015, N=401.

have had the counselling for lifestyle modification. Around two third (66.3\%) of the respondents were regular Khat chewers (Table 2).

\section{Healthy lifestyle adherence}

Adherence to the healthy lifestyle was $62.1 \%$ : each patient was found to be in line with at least one recommendation. Out of total respondents $8(2 \%)$ were adherent to only two, $34(8.5 \%)$ adherent to three and $26.7 \%$ adherent to four recommendations. Out of 401 respondents, $28.7 \%$ of the respondents were adherent to all recommendations. 


\begin{tabular}{|c|c|c|c|}
\hline \multicolumn{2}{|c|}{ Variables } & \multirow{2}{*}{$\begin{array}{c}\text { Frequency } \\
182\end{array}$} & \multirow{2}{*}{\begin{tabular}{|c|}
$\begin{array}{c}\text { Percentage } \\
\text { (\%) }\end{array}$ \\
45.4 \\
\end{tabular}} \\
\hline Years after diagnosis & $1-5$ years & & \\
\hline & $6-10$ years & 142 & 35.4 \\
\hline & $10+$ & 77 & 19.2 \\
\hline \multirow[t]{4}{*}{ Current BP category } & Normal & 45 & 11.2 \\
\hline & Prehypertension & 61 & 15.2 \\
\hline & Stage 1 & 227 & 56.6 \\
\hline & Stage 2 & 68 & 17 \\
\hline \multirow[t]{2}{*}{ BP control } & Controlled & 89 & 22.2 \\
\hline & Not controlled & 312 & 77.8 \\
\hline \multirow[t]{4}{*}{ Family/friend support } & Not at all & 56 & 14 \\
\hline & A little & 65 & 16.2 \\
\hline & Somewhat & 114 & 28.4 \\
\hline & A lot & 166 & 41.4 \\
\hline \multirow[t]{3}{*}{ Comorbidity } & None & 135 & 33.7 \\
\hline & One & 192 & 47.9 \\
\hline & Two or more & 74 & 18.4 \\
\hline \multirow[t]{3}{*}{ No of pills for hypertension } & One & 180 & 44.9 \\
\hline & Two & 182 & 45.4 \\
\hline & More than two & 39 & 9.7 \\
\hline \multirow[t]{2}{*}{ Knowledge } & Good & 336 & 83.8 \\
\hline & Poor & 65 & 16.2 \\
\hline \multirow[t]{2}{*}{ Clues to action } & Have & 371 & 92.5 \\
\hline & Haven't & 30 & 7.5 \\
\hline \multirow[t]{2}{*}{ Visit hospital } & Sometimes & 43 & 10.7 \\
\hline & Always & 358 & 89.3 \\
\hline \multirow[t]{2}{*}{ Use alternative medicine } & Yes & 27 & 6.7 \\
\hline & No & 374 & 93.3 \\
\hline \multirow[t]{2}{*}{ Khat chewing } & Yes & 135 & 33.7 \\
\hline & No & 266 & 66.3 \\
\hline
\end{tabular}

Table 2: Blood pressure and related conditions among hypertensive patients attending Hiwot Fana Specialized University Hospital and Jugola Hospital from February 13 to March 16, 2015, N=401.

\section{Factors associated with healthy lifestyle adherence}

The association of the selected socio-demographic, HTN and other related characteristics on adherence status to the healthy lifestyle was investigated using both the bivariate and multivariate logistic regression technique. On the bivariate analysis; age, marital status, religion, ethnicity, work category, educational status, distance, monthly income, BP control, comorbidity, knowledge of HTN, hospital visit and chewing Khat were associated with adherence to healthy lifestyle and included into multiple logistic regression. On the multivariate analysis, marital status, educational level, distance, BP control, hospital visit and Khat chewing were significantly affecting the adherence to recommended lifestyle. Widowed respondents were 4.29 times more likely to adhere to the healthy lifestyle as compared to married respondents (Adjusted Odds Ratios, AOR=4.29 CI=1.20-15.4, 0.025). Respondents who can read and write were $2.63(\mathrm{AOR}=2.63 \mathrm{CI}=1.19-5.82,0.017)$ times more adherent to the healthy lifestyle when compared with respondents who can't read and write. Respondents educated primary school (1-8) were $2.32(\mathrm{AOR}=2.32 \mathrm{CI} 1.13-4.75,0.022)$ times more likely to adhere to the healthy lifestyle when compared with respondents who can't read and write. Respondents who come from less than one kilometer far from their respective hospitals were 2.46 times more likely to adhere to the healthy lifestyle as compared with respondents come from $3 \mathrm{~km}$ and far $(\mathrm{AOR}=2.46 \mathrm{CI}=1.26-4.84,0.009)$. In this study, respondents who visit their hospital appointment regularly were 3.76 times more likely to adhere to the healthy lifestyle as compared to those who were not
$(\mathrm{AOR}=3.76 \mathrm{CI} 1.56-9.07,0.003)$. Khat non-chewers were 4.06 times more likely to adhere to the healthy lifestyle as compared with Khat chewers $(\mathrm{AOR}=4.06 \mathrm{CI}=2.21-7.48,0.000)$ (Table 3$)$.

\section{Discussion}

Good adherence to healthy lifestyle lower the BP to optimal level, prevent or delay the chance of developing of hypertension, enhance the efficacy antihypertensive drug, decrease cardiovascular risk and prevent fatal complication of hypertension. Poor adherence to the recommended healthy lifestyle is one of the most important reasons for uncontrolled HTN, serious complications \& wastage of healthcare resources. Since the success of therapies is dependent upon the level of adherence to healthy lifestyle, this study was aimed to assess the adherence level of hypertensive patients to recommended healthy lifestyle.

The overview of the community of the partcipants in this study shows high prevalence of smokers (12\%) even though the figure diminuted (27\%) from the 2011 EDHS data. This number is higher than the pooled national figure and also any region of Ethiopia next to Somali. Likewise the prevalence of alcohol consumption in the community is high; with sex variation $11.2 \%$ among women to $16 \%$ to men. Childhood obesity and overweight increasing among the study population where being obese is believed the fortune and it is much more common among indviduals in the highest wealth quintile (10\%). Other unhealthy behaviours like Khat chewing are commonly practiced in the country as well as the study community $[29,30,33]$.

In this study, $62.1 \%$ of the respondents were adhered to at least five from the six recommended healthy lifestyles for hypertensive patients and are considered as adherent. This is lower than the WHO recommendation of $80 \%$ adherence. This could be explained by the low socioeconomic status. Furthermore, it may also be due to lack of the knowledge regarding the importance of recommended healthy lifestyle to control HTN and difficulty to adapt those healthy lifestyles among the study participants.

However, it is more than twice of the study conducted on HTNrelated knowledge, attitudes and lifestyle practices among hypertensive patients in a suburban Nigerian community 30\% [34]. The possible explanation for this could be study participants in the Nigerian study were from the suburban area while participants of the current study were from one of the biggest towns in the country; which would bring the difference in awareness of healthy lifestyle importance and even ease of adapting those recommended health lifestyles in daily life. In this study out of the total; $28.7 \%$ of the respondents were adherent to all recommendations. This result is in line with the study conducted by Tibabu et al. [31]. The possible explantion could be the sociocultural and economic similarity of the study subjects.

Out of 401 hypertensive participants; $62.3 \%$ reported the exercise adherence whereas $81.8 \%$ participants report properly follows DASH diets. As of the current study; $81.5 \%$ of all participants reported never smoked or stopped smoking before 12 months prior to data collection. Meanwhile, $95.8 \%$ of the participants never engaged in any type of alcohol drinking or less than $30 \mathrm{~mL}$ net alcohol daily consumption. The study also demonstrates that $98.5 \%$ of the participants were found to be adherent to the recommended salt intake limit (less than $2.4 \mathrm{~g}$ dairy consumption). In this study, $56.4 \%$ of the participants have the ideal body weight (the calculated BMI is within the limit of 18.5 to 24.9).

Exercise adherence is higher than the result of the study finding of Addis Abeba 43\%, Israel 50\% and Turkey 31\% and Colombia 
Citation: Nadewu AN, Geda B (2018) Adherence to Healthy Lifestyle among Hypertensive Patients in Harar Region, Eastern Ethiopia. Prim Health Care 8: 308. doi: 10.4172/2167-1079.1000308

Page 5 of 7

\begin{tabular}{|c|c|c|c|c|c|c|}
\hline \multirow{2}{*}{ Variables } & \multirow{2}{*}{ Category } & \multicolumn{2}{|c|}{ Healthy Lifestyle adherence } & \multirow{2}{*}{ Crude odds ratio (COR) } & \multirow{2}{*}{ Adjusted Odd Ratios (AOR) } & \multirow{2}{*}{ P-value } \\
\hline & & Adherent & Nonadherent & & & \\
\hline \multirow{3}{*}{ Age } & $18-39$ & 16 & 6 & $2.12(0.80-5.64)$ & $2.39(0.72-7.83)$ & 0.157 \\
\hline & $40-60$ & 115 & 52 & $1.76(1.15-2.70)^{\star}$ & $1.62(0.91-2.86)$ & 0.099 \\
\hline & $60+$ & 118 & 94 & 1.00 & 1.00 & \\
\hline \multirow{4}{*}{ Marital status } & Married & 175 & 108 & 1.00 & 1.00 & \\
\hline & Widowed & 21 & 4 & $3.24(1.08-9.70)$ & $4.29(1.20-15.4)$ & $0.025^{\star \star}$ \\
\hline & Divorced & 38 & 32 & $0.73(0.43-1.24)$ & $1.02(0.51-2.02)$ & 0.966 \\
\hline & Single/separate & 15 & 8 & $1.16(0.48-2.82)$ & $1.91(0.58-6.32)$ & 0.290 \\
\hline \multirow{3}{*}{ Religion } & Muslim & 82 & 71 & 1.00 & 1.00 & \\
\hline & Protestant & 27 & 13 & $1.80(0.86-3.75)$ & $0.51(0.15-1.73)$ & 0.282 \\
\hline & Orthodox & 140 & 68 & $1.78(1.16-2.74)^{*}$ & $0.73(0.28-1.88)$ & 0.513 \\
\hline \multirow{4}{*}{ Ethnicity } & Amhara & 133 & 63 & 1.00 & 1.00 & \\
\hline & Harari & 33 & 30 & $0.52(0.29-0.93)^{*}$ & $0.54(0.17-1.70)$ & 0.291 \\
\hline & Oromo & 73 & 48 & $0.72(0.45-1.16)$ & $0.87(0.38-2.02)$ & 0.748 \\
\hline & Others & 10 & 11 & $0.43(0.17-1.07)$ & $0.52(0.17-1.60)$ & 0.253 \\
\hline \multirow{5}{*}{$\begin{array}{l}\text { Educational } \\
\text { status }\end{array}$} & Illiterate/can't read & 61 & 68 & 1.00 & 1.00 & \\
\hline & Illiterate/can read & 40 & 20 & $2.23(1.18-4.22)$ & $2.63(1.19-5.82)$ & $0.017^{* \star}$ \\
\hline & Primary & 83 & 31 & $2.99(1.74-5.11)$ & $2.32(1.13-4.75)$ & $0.022^{* *}$ \\
\hline & Secondary & 51 & 25 & $2.27(1.26-4.10)^{*}$ & $1.38(0.58-3.28)$ & 0.462 \\
\hline & College/university & 14 & 8 & $1.95(0.77-4.97)$ & $1.42(0.37-5.44)$ & 0.607 \\
\hline \multirow{6}{*}{ Work category } & Governmental & 50 & 18 & 1.00 & 1.00 & \\
\hline & Nongovernmental & 17 & 16 & $0.38(0.16-0.91)^{\star}$ & $0.47(0.16-1.36)$ & 0.165 \\
\hline & Housewife & 85 & 59 & $0.52(0.28-0.98)^{*}$ & $0.47(0.17-1.28)$ & 0.141 \\
\hline & Farmer & 17 & 19 & $0.32(0.14-0.75)^{*}$ & $1.21(0.32-4.64)$ & 0.779 \\
\hline & Merchant & 23 & 18 & $0.46(0.20-1.04)$ & $0.66(0.23-1.87)$ & 0.432 \\
\hline & Others & 57 & 22 & $0.93(0.45-1.94)$ & $1.06(0.36-3.08)$ & 0.917 \\
\hline \multirow{3}{*}{$\begin{array}{l}\text { Distance from } \\
\text { hospital }\end{array}$} & Less than a $\mathrm{Km}$ & 120 & 51 & $2.39(1.47-3.91)$ & $2.46(1.26-4.84)$ & $0.009^{* *}$ \\
\hline & $1-3 \mathrm{~km}$ & 72 & 43 & $1.70(1.01-2.88)^{\star}$ & $1.46(0.75-2.84)$ & 0.267 \\
\hline & $3 \mathrm{~km}$ and more & 57 & 58 & 1.00 & 1.00 & \\
\hline \multirow{3}{*}{ Monthly income } & $<300$ birr & 102 & 42 & 1.00 & 1.00 & \\
\hline & 300-699 birr & 85 & 76 & $0.46(0.29-0.74)^{*}$ & $0.53(0.25-1.11)$ & 0.093 \\
\hline & 700 and more & 62 & 34 & $0.75(0.43-1.30)$ & $0.91(0.38-2.19)$ & 0.829 \\
\hline \multirow{2}{*}{ BP control } & Controlled & 76 & 13 & $4.70(2.50-8.81)$ & $4.03(1.93-8.42)$ & $0.000^{* *}$ \\
\hline & Uncontrolled & 173 & 139 & 1.00 & 1.00 & \\
\hline \multirow{3}{*}{ Co morbidity } & None & 88 & 47 & 1.00 & 1.00 & \\
\hline & One & 122 & 70 & $0.93(0.59-1.48)$ & $1.48(0.82-2.68)$ & 0.197 \\
\hline & Two or more & 39 & 35 & $0.59(0.33-1.06)$ & $0.63(0.29-1.38)$ & 0.250 \\
\hline \multirow{2}{*}{ Knowledge } & Good & 27 & 38 & $2.74(1.59-4.72)$ & $1.22(0.57-2.60)$ & 0.616 \\
\hline & Poor & 222 & 114 & 1.00 & 1.00 & \\
\hline \multirow{2}{*}{ Visit hospital } & Frequently & 236 & 122 & $4.46(2.25-8.86)$ & $3.76(1.56-9.07)$ & $0.003^{* *}$ \\
\hline & Sometimes & 13 & 30 & 1.00 & 1.00 & \\
\hline \multirow{2}{*}{ Khat chew } & Yes & 9 & 18 & 1.00 & 1.00 & \\
\hline & No & 240 & 134 & $3.73(2.41-5.77)$ & $4.06(2.21-7.48)$ & $0.000^{* *}$ \\
\hline
\end{tabular}

Table 3: Comparison of socio-demographic and health-related characteristics with healthy lifestyle adherence among hypertensive patients attending Hiwot Fana Specialized University Hospital and Jugola Hospital from February 13 to March 16, 2015, N=401.

$46.6[20,27,32,35]$. The possible explanation for the discrepancies is methodological factor where the current study use self-reports of participants. It could also be due to the socio-economic variation, where in this study the participants are from low income community and obligated to walk for their daily issues that require travel to. Diet adherence is higher than that of Israel $50 \%$ and turkey $65 \%[20,35]$. This might be due to the economic class, as the nation is more industrialized the chance of adhering to diet decrease due to easy access of nonrecommended diets. It may be due to the difference in the methodology they used.

Out of the total, $18.5 \%$ were smokers which are higher than that of Israel $13 \%$. This might be due to poor knowledge of the effect of smoking on BP. However, this figure is less than the study conducted 
in addis abeba (34.4\%) [31]. Fifty-six percent of the respondents had normal BMI which is higher than the study of Israel 35\% [20].

In this study, illiterate who can't read and write were less adhered to the healthy lifestyle as compared to literate who can read and write and primary educated. It may be due to they can't read information sources like fosters, leaflets and similar written material for HTN. In this study, widowed respondents were 4.29 times more likely to adhere to the healthy lifestyle as compared to married respondents. It might be due to their choice of the lifestyle as diet selection, salt restriction, alcohol limitation and exercise not affected by partner than married. Married respondent gives more concern for the partner choice. In this study, the respondents with BP under control were 4 times more adherent to lifestyle. It is clear that why their BP was under control. The respondents who visit the hospital regularly are 3.76 times more adherent to the healthy lifestyle than those visiting their appointment sometimes. This is due to the regular visitor get the counselling and find update information each time they visit their physician.

Khat chewing was negatively affected by the lifestyle modification. It may be due to the positive association of Khat chewing with alcohol drink \& smoking as revealed by different studies. It could also be due to the psychoactive effect of Khat, thus result in disremember and overlook the adherence to healthy lifestyle $[33,36]$.

In this study, the good adherence to the healthy lifestyle modalities improves the BP control of an individual. There is the dearth of the similar study conducted in the study area and the country, to compare and discuss. The study used self-report of the patients and thus it is prone to biases. It doesn't assess some biochemical tests like blood cholesterol, lipid and other.

\section{Conclusion}

In this study the rate of adherence to recommended healthy lifestyle found to be suboptimal. Factors such as educational level, controlled BP and hospital visit were positively associated with lifestyle modifications; while marital status, distance from the hospital and Khat chewing were negatively associated with it. There is lack of awareness about the HTN and the importance of adherence to management regimen.

Cognizant of the study facts revealed more efforts should be done for awareness regarding not only medication but special emphasis should be put on healthy lifestyle adherence.

\section{Availability of Data and Materials}

The data and materials of this study is available with the corresponding author and can be shared upon reasonable request.

\section{Competing Interests}

The authors declare no competing interests

\section{Acknowledgment}

We are very grateful to all study participants for their commitment to responding to our questionnaires.

\section{References}

1. Kasper DL, Hauser SL, Longo DL, Jameson DL, Loscalzo J (2015) Harrison's principles of internal medicine. McGraw-Hill Companies, Inc.

2. Beevers DG, Lip GYH, O'Brien E (2014) ABC of Hypertension. USA: Blackwell Publishing.

3. Hinkle JL, Cheever KH (2010) Brunner and Sudderth's Text Book of Medical Surgical Nursing. Philadelphia: Lippincott Williams and Wilkins.

4. Kibret KT, Mesfin YM (2015) Prevalence of hypertension in Ethiopia: A systematic meta-analysis. Public Health Rev 36: 14.
5. WHO (2013) A global brief on Hypertension, silent killer, global public health crisis.

6. Fukushima K, Morokuma S, Tsukimori K, Murata M, Wake N (2012) Blood pressure measurements within the JNC7 pre-hypertensive range after 32 weeks of gestation are a risk factor for decreased fetal growth. Hypertens Res 2012. 35: 128-130.

7. Lerma EV, RosnerMH, Perazella MA (2009) Current Diagnosis \& Treatment Of Nephrology and Hypertension. USA: McGraw-Hill Companies, Inc.

8. Dennis T (2011) Medication adherence and associated barriers in hypertension management in India. CVD Prevention and Control 6: 9-13.

9. Mancia G, Grassi G (2008) Manual of Hypertension of the European Society of Hypertension. USA: Library of Congress.

10. Kearney PM, Whelton M, Reynolds K, Muntner P, Whelton PK, et al. (2005) Global burden of hypertension: Analysis of worldwide data. Lancet 365: 217 223.

11. WHO (2003) Adherence to long-term therapies: Evidence for action.

12. Kastarinen MJ, Puska PM, Korhonen MH, Mustonen JN, Salomaa VV, et al. (2002) Non-pharmacological treatment of hypertension in primary health care: A 2 year open randomized controlled trial of lifestyle intervention against hypertension in eastern Finland. J Hypertens 20: 2505-2512.

13. Mörike K, Boesen N, Mikus G, Schwab M (1998) Drug therapy information: A service provided by clinical pharmacologists for physicians in private practice and hospitals. Eur J Clin Pharmacol 54: 573-574.

14. Association AH (2008) Lifestyle modification, heart foundation guide to management of hypertension.

15. Thakkar RB, Oparil S (2001) Effects of ACE inhibitors, calcium antagonists and other blood pressure-lowering drugs. Curr Hypertens Rep 3: 227-228.

16. Schillaci G, Vaudo G (2001) Effects of ACE inhibitors, calcium antagonists and other blood-pressure-lowering drugs: Results of prospectively designed overviews of randomized trials. Ital Heart J Suppl 2: 799-802.

17. Neal B, MacMahon S, Chapman N (2000) Effects of ACE inhibitors, calcium antagonists and other blood-pressure-lowering drugs: Results of prospectively designed overviews of randomised trials. Lancet 356: 1955-1964.

18. Hedner T, Narkiewicz K, Kjeldsen SE (2005) Hypertension control-A global challenge. Blood Press Suppl 1: 4-5.

19. Annamalai C, Govindaraja C, Chandramouli C (2011) Prevalence, awareness and control of hypertension in estate workers in Malaysia. N Am J Med Sci 3 . 540-543.

20. Heymann AD, Gross R, Tabenkin H, Porter B, Porath A (2011) Factors associated with hypertensive patients' compliance with recommended lifestyle behaviors. Isr Med Assoc J 13: 553-557.

21. Saeed AA, Al-Hamdan NA, Bahnassy AA, Abdalla AM, Abbas MA, et al. (2011) Prevalence, awareness, treatment and control of hypertension among Saudi adult population: A national survey. Int J Hypertens 2011: 174135

22. Decoste M, Vanobberghen R, Borgermans L, Devroey D (2013) Uncontrolled hypertension among black Africans in the city of Brussels: A case-control study. Eur Rev Med Pharmacol Sci 17: 886-894.

23. Babiker FA, Elkhalifa LA, Moukhyer ME (2013) Awareness of hypertension and factors associated with uncontrolled hypertension in Sudanese adults. Cardiovasc J Afr 24: 208-212.

24. Chiuve SE, Fung TT, Rexrode KM, Spiegelman D, Manson JE, et al. (2011) Adherence to a low-risk, healthy lifestyle and risk of sudden cardiac death among women. JAMA 306: 62-69.

25. Lv J, Yu C, Guo Y, Bian Z, Yang L, et al. (2017) Adherence to healthy lifestyle and cardiovascular diseases in the Chinese population. J Am Coll Cardiol 69 1116-1125.

26. Hamer M (2010) Adherence to healthy lifestyle in hypertensive patients: Ample room for improvement? J Hum Hypertens 24: 559-560.

27. Fang J, Moore L, Loustalot F, Yang Q, Ayala C (2013) Reporting of adherence to healthy lifestyle behaviors among hypertensive adults in the 50 states and the district of Columbia, 2013. J Am Soc Hypertens 10: 252-262.e3.

28. Neminqani DA, El-Shereef EAA, Thubiany MM (2015) Hypertensive patients: Self-care management. Int J Science Res 4: 1705-1714. 
Citation: Nadewu AN, Geda B (2018) Adherence to Healthy Lifestyle among Hypertensive Patients in Harar Region, Eastern Ethiopia. Prim Health Care 8: 308. doi: 10.4172/2167-1079.1000308

29. Michael M (2016) National guideline on major NCDs 2016.

30. Central Statistical Agency (2017) Ethiopia demographic and health survey 2016.

31. Tibebu A, Mengistu D, Negesa L (2017) Adherence to recommended lifestyle modifications and factors associated for hypertensive patients attending chronic follow-up units of selected public hospitals in Addis Ababa, Ethiopia. Patient Prefer Adherence 11: 323-330.

32. Hareri HA, Abebe M (2013) Assessments of adherence to hypertension managements and its influencing factors among hypertensive patients attending black lion hospital chronic follow up unit, Addis Ababa, Ethiopia-a cross-sectional study. IJPSR 4: 1086-1095.
33. Tesfaye F, Byass P, Wall S, Berhane Y, Bonita R (2006) Association of smoking and khat (Catha edulis Forsk) use with high blood pressure among adults in Addis Ababa, Ethiopia. Prev Chronic Dis 5: A89.

34. Iyalomhe GBS, lyalomhe SII (2010) Hypertension-related knowledge, attitudes and life-style practices among hypertensive patients in a sub-urban Nigerian community. J Public Health Epidemiol 2: 71-77.

35. Uzun S, Kara B, Yokuşoğlu M, Arslan F, Yilmaz MB, et al. (2009) The assessment of adherence of hypertensive individuals to treatment and lifestyle change recommendations. Anadolu Kardiyol Derg 9: 102-109.

36. Damena T, Mossie A, Tesfaye M (2011) Khat chewing and mental distress: A community based study, in Jimma city, southwestern Ethiopia. Ethiop J Health Sci 21: $37-45$ 